Bazzini, D., Curtin, L., Joslin, S., Regan, S., \& Martz, D. (2010). Do animated Disney characters portray and promote the beauty-goodness stereotype? Journal of Applied Social Psychology, 40(10): 2687-2709. (Oct 2010)

Published by Wiley-Blackwell (ISSN: 1559-1816). DOI: 10.1111/j.1559-1816.2010.00676.x The definitive version is available at www3.interscience.wiley.com.

\title{
Do Animated Disney Characters Portray and Promote the Beauty-Goodness Stereotype?
}

Doris Bazzini, Lisa Curtin, Serena Joslin, Shilpa Regan, Denise Martz

\begin{abstract}
Disney movies are frequently cited as a source of the what-is-beautiful-is-good stereotype. Two studies (a) assessed prevalence of the stereotype across animated Disney movies; and (b) examined whether exposure to such films influences children's judgments of peers. In Study 1, human characters in 21 films were rated on attractiveness, goodness, and character outcome. Regression analyses demonstrated that attractiveness of a character was a significant predictor of the character's portrayal. In the second study, 42 children (ages 6-12) were exposed to either a high or low beauty-biased film and then rated target peers. Children rated the attractive target more favorably than the less attractive target. However, film exposure did not increase children's use of the stereotype.

The films of Walt Disney have served as icons of childhood over the last century. The Disney Corporation's success is evidenced in its financial fortitude. In 1995, Walt Disney Company had the biggest market share, relative to the number of releases, at 19\% (Smith \& Thompson, 1996). In 1997, Disney had sales of nearly $\$ 24$ billion. This made Disney the world's second largest media firm behind Time Warner. As of mid-2007, Disney was a Dow 30 company, with annual revenues of nearly $\$ 34$ billion in its previous fiscal year ("Disney Acquires Club Penguin,"
\end{abstract}


2007). Films for children contribute hundreds of millions of dollars to Disney annually (Robertson, 1998). One researcher suggested that Disney films inspire at least as much cultural authority and legitimacy for teaching specific roles, values, and ideals than more traditional sites of learning, such as public schools, religious institutions, and the family (Giroux, 1995). Their popularity among children and adults has led a handful of researchers to assess character portrayals within these films. For instance, Robinson, Callister, Magoffin, and Moore (2007) recently evaluated Disney's portrayal of the elderly.

Disney characters have commonly been cited in social psychological literature as evidence of the stereotype known as "what is beautiful is good" (Dion, Berscheid, \& Walster, 1972). For example, Eagly, Ashmore, Makhijani, and Longo (1991) proposed that examples of the stereotype are reflected in children's books and television in which the heroic prince and virtuous princess are attractive, but the wicked witch and evil giant are ugly. More specifically, Myers (2002) asserted, "Children learn the stereotype quite early. Snow White and Cinderella are beautiful and kind. The witch and the stepsisters are ugly and wicked" (p. 428).

Although it may be seemingly apparent that the preponderance of virtuous characters in these films (e.g., Ariel of The Little Mermaid, Belle of Beauty and the Beast, Sleeping Beauty) are indeed beautiful, and evil characters are unattractive (e.g., Ursula of The Little Mermaid, Cruella De Vil of 101 Dalmatians), no studies to date have empirically evaluated whether the association between physical attractiveness and moral character is reliably depicted.

Furthermore, assessments of the impact of these films on children's judgments of others relative to the physical attractiveness stereotype have not occurred. Thus, two studies were conducted to examine the prevalence of the stereotype in animated Disney films and their potential impact on peer judgments among children.

\section{WHAT IS BEAUTIFUL IS GOOD}

Seminal social psychological research conducted 30 years ago documented the what-isbeautiful-is-good stereotype (Dion et al., 1972), or the perception that physically attractive individuals possess more positive qualities and experience more satisfying life outcomes than do unattractive individuals. This physical attractiveness (PA) stereotype has been observed in social and professional contexts (Abramowitz \& O'Grady, 1990; Cash \& Kilcullen, 1985; Farley, Chia, \& Allred, 1998) and has been shown in Western as well as non-Western cultures, despite differences in perceptions surrounding PA across cultures (Chen \& Shaffer, 1997).

Though the uniformity of the stereotype across personality traits and social judgments has been called into question by a meta-analysis of the relevant literature, Eagly et al. (1991) found that the stereotype was most robust for perceptions of social competency. People expect attractive individuals, relative to those who are less attractive, to be more socially adept and popular and to have similar positive characteristics (e.g., be fun loving). Furthermore, the results supported a moderate expectation for physically attractive individuals to be intellectually competent, and little or no expectation for such individuals to be more psychologically adjusted or to possess greater integrity and concern for others than less physically attractive individuals. Across decades of 
studies, less attractive individuals were never perceived more positively in any assessed category than more attractive individuals (Eagly et al., 1991).

The media have been implicated as a common contributor to the PA stereotype. Eagly et al. (1991) stated that while the media do not consistently portray "beauty is good" and "ugly is bad," they frequently encourage these associations. This association is especially true in advertising in which attractive models appear in positive settings. For example, in a study of over 4,000 commercials, Downs and Harrison (1985) found some form of attractiveness message in nearly $25 \%$ (1 out of 3.8 ) of the commercials.

Another form of media often thought to portray the what-is-beautiful-is-good stereotype is movies. Smith, Mclntosh, and Bazzini (1999) conducted a study that looked at the PA stereotype in the top-grossing films from 1940 to 1989. Raters watched 100 films (20 from each decade) and rated the central, secondary, and peripheral characters on a list of social attributes and life outcomes. They found that the attractiveness of a character was strongly and positively correlated with how morally good that character was portrayed. Greater physical beauty was associated with higher levels of romantic activity and better life outcomes, and was weakly related to higher intelligence and slightly lower levels of aggression. These findings were true for both male and female characters. Character centrality to the plot was also related to higher levels of character attractiveness relative to secondary or peripheral character portrayals.

\section{STUDY 1}

Smith et al.'s (1999) investigation excluded the genre of animated children's movies, including Disney films. As previously discussed, Disney films are specifically named as examples of the linking of beauty and goodness by social psychology researchers, particularly in textbooks (e.g., Myers, 2002). However, despite popular anecdotal evidence of the PA stereotype, the question of whether or not Disney consistently portrays this stereotype has yet to be answered empirically. Possibly, those who cite Disney as evidence of the stereotype selectively attend to a handful of characters that exhibit the stereotype.

The purpose of Study 1 is to assess the prevalence of the PA stereotype in animated Disney films. Raters evaluated the PA of the main and supporting characters in each film, as well as each character's portrayed goodness, intelligence, aggressiveness, romantic involvement, and life outcome. It is anticipated that the what-is-beautiful-is-good stereotype will be highly prevalent and consistently portrayed within the animated Disney films. Given Smith et al.'s (1999) findings with top-grossing films, it is also anticipated that role, beauty, and the interaction of beauty by role will be significant predictors of goodness. Additionally, it is expected that central characters will be portrayed more favorably, overall, than will secondary or peripheral characters. As gender was not a significant predictor of favorability of a character in Smith et al.'s study, it is not expected to be a significant predictor in this analysis. 


\section{METHOD}

\section{Selection of Target Films}

A list of animated, box-office Disney films since 1938 was first compiled (consisting of 40 films). Box-office films were selected because they were assumed to be the most commercially popular and would, therefore, reach the largest audience. Given that animal characters are often the focus of animated Disney films (e.g., Lady and the Tramp, The Lion King, Dumbo) and that it would be beyond the scope of this research to determine if stereotypes about animal characters generalize to human characters, only films with at least three characters who had human facial characteristics were included. That is, human characters and characters that were humanlike with regard to facial composition (e.g., Ariel in The Little Mermaid) were rated. Using these criteria, 21 movies were included in the sample, while Alice in Wonderland was an additional movie that was used for the training of coders. Table 1 provides a complete list of the movies. 
Table 1

Intercorrelations Between Beauty and Goodness and Number of Rated Characters Per Movie

\begin{tabular}{llc}
\hline Movie & $r$ & Rated characters \\
\hline Aladdin & .751 & 5 \\
Atlantis & .022 & 14 \\
Beauty and the Beast & .439 & 5 \\
Black Cauldron & $.824^{*}$ & 8 \\
Brother Bear & -.748 & 4 \\
Cinderella & $.915^{* *}$ & 8 \\
101 Dalmatians & $.823^{*}$ & 6 \\
The Emperor's New Groove & $.782^{*}$ & 7 \\
Hercules & .434 & 9 \\
The Hunchback of Notre Dame & .066 & 6 \\
Lilo and Stitch & $.931^{*}$ & 6 \\
The Little Mermaid & .591 & 8 \\
Mulan & $.618^{*}$ & 14 \\
Peter Pan & $.808^{* *}$ & 11 \\
Pinocchio & $.876^{*}$ & 6 \\
Pocahontas & $.688^{*}$ & 12 \\
The Rescuers & .935 & 3 \\
Sleeping Beauty & .315 & 9 \\
Snow White & .533 & 12 \\
Sword in the Stone & $.838^{*}$ & 6 \\
Tarzan & .662 & 4 \\
\hline
\end{tabular}

${ }^{*}$ Significant at .05 (two-tailed). ${ }^{* *}$ Significant at .01 (two-tailed).

\section{Rating Procedure}

Institutional Review Board Approval to conduct this research was granted, and all procedures were in compliance with the American Psychological Association's (APA, 2002) ethical standards for research practice. The same rating instrument and procedure employed by Smith et al. (1999) was utilized in this study. Extensive training materials were provided for each of four raters, and at least three people, blind to one another, rated each film. Raters were instructed to use an 11-point scale to rate all 163 characters identified by name. The characters were rated on the following categories: 
1. Attractiveness. Ratings of PA were based on a scale ranging from 0 (extremely unattractive) to 10 (extremely attractive).

2. Aggressiveness. Aggressiveness was defined as physical or verbal abuse of other people. Ratings were made on a scale ranging from 0 (not at all aggressive) to 10 (extremely aggressive).

3. Goodness. Raters assessed the character's moral virtue on a scale ranging from 0 (extremely immoral) to 10 (extremely moral).

4. Intelligence. Raters assessed the character's intelligence on a scale ranging from 0 (extremely unintelligent) to 10 (extremely intelligent).

5. Outcome. At film's end, each participant rated the character's outcome on a scale of 0 (extremely negative) to 10 (extremely positive).

6. Romantic involvement. As a result of the inexplicitness of most animated films, raters were asked to estimate, according to context, the amount of romantic or sexual activity in which a character was involved. Participants rated a character's real or implied romantic involvement, sexual involvement, or both on a scale ranging from 0 (totally inactive) to 10 (extremely active).

The raters first rated a character's sex and role in the film as either central (i.e., leading character), secondary (i.e., supporting character), or peripheral (i.e., appearing in only a few scenes). Although trait ratings were generally made at the film's end, PA was rated the first time a character was shown in the film in order to eliminate the possibility of another aspect of the character influencing the PA rating. To eliminate raters influencing each other, raters did not discuss a film until all ratings had been completed.

\section{Rater Reliability}

We used four raters ( 3 females, 1 male) in this study. Of the four raters, two evaluated every movie, while the other two raters each evaluated approximately half of the movies. Thus, every movie was evaluated by three raters.

The total number of characters rated was 163. There were significantly more female $(n=103)$ than male characters $(n=60), \mathrm{x}^{2}(1, N=163)=11.34, p=.001$. A breakdown of character role by gender demonstrates that of the 39 central characters, 19 were male and 20 were female, $\mathrm{X}^{2}(1, N=39)=0.03, p=.87$. There were 59 characters that were categorized as secondary to the plot (16 male, 43 female), $X^{2}(1, N=59)=12.36, p=.0001$. Finally, 65 characters were categorized as peripheral to the plot (25 male, 40 female), $X^{2}(1, N=65)=3.46, p=.06$.

For each of the 163 characters in these films, the reliability of the raters was analyzed. Because the rating data were continuous in nature and multiple judges were used for each dimension, we used Cronbach's alpha as our estimate of interrater reliability (for a review, see Stemler, 2004). An exact consensus estimate between pairs of raters (e.g., Cohen's $\mathrm{k}$ ) was deemed overly conservative, given 11 levels of each dimension rated by three raters. Consistent with the alphas reported by Smith et al. (1999), our raters showed considerable agreement across dimensions: attractiveness $=.90 ;$ aggressiveness $=.76 ;$ goodness $=.93 ;$ intelligence $=.69$; 
outcome at the movie's end $=.88$; and romantic involvement $=.86$. Since interrater reliability estimates were roughly $70 \%$ or better across dimensions, composite trait ratings for each character were then created by averaging the three raters' evaluations of each trait.

The intercorrelations between goodness and PA for each movie that raters viewed are shown in Table 1. Across all 21 movies, the correlation between the beauty of a character and his or her demonstrated goodness was .61 $(p=.0001)$. However, prior to the study, raters may have themselves believed that more attractive people are better people and, therefore, biased their ratings within this study to produce this relationship between PA and goodness within the characters.

To investigate this possibility, a sample of undergraduate volunteers $(N=35)$ rated the attractiveness (on the same 11-point scale that was used earlier) of slides of 36 film characters, which constituted $22 \%$ of the original sample of characters. The attractiveness ratings of the film characters by this undergraduate sample were averaged and correlated with raters' assessments of character attractiveness, resulting in a correlation of .91 $(p=.0001)$. Finally, the undergraduate students' assessments of character attractiveness were correlated with raters' assessments of character goodness, resulting in a significant positive correlation $(r=.65$, $p=.0001)$. A comparison of the two correlations between character attractiveness and goodness generated by the undergraduate class sample $(r=.65)$, versus that of the movie raters $(r=.61)$, demonstrates no statistical difference, $t(33)=0.72, p>.05$, suggesting that the raters in the study were not more biased than was the control sample of raters.

\section{RESULTS}

In order to address the extent to which animated Disney films portray an association between PA and goodness, we conducted Pearson's product-moment correlations. Table 2 presents the means and standard deviations for all measured variables, and Table 3 shows the intercorrelations across variables. All variables were significantly correlated with PA at .01. As ratings of beauty increased, so did ratings of friendliness, goodness, intelligence, favorability of the character's outcome, and romantic involvement. All correlations with PA were positive, except for aggressiveness $(r=-.24, p=.01)$. That is, as the ratings of aggressiveness increased for a given character, the ratings of PA decreased. 
Table 2

Means of Measured Variables

\begin{tabular}{lcc}
\hline Variable & $M$ & $S D$ \\
\hline Aggressiveness & 4.11 & 2.43 \\
Beauty & 4.98 & 2.40 \\
Friendliness & 6.11 & 2.63 \\
Goodness & 6.15 & 2.89 \\
Intelligence & 6.02 & 1.26 \\
Outcome & 6.69 & 2.88 \\
Romantic involvement & 1.14 & 1.83 \\
Socioeconomic status & 6.03 & 2.26 \\
\hline
\end{tabular}

Table 3

Intercorrelations Among Measured Variables

\begin{tabular}{lccccccc}
\hline Variable & 1 & 2 & 3 & 4 & 5 & 6 & 7 \\
\hline 1. Aggressiveness & - & & & & & & \\
2. Beauty & $-.247^{* *}$ & - & & & & & \\
3. Friendliness & $-.669^{* *}$ & $.565^{* *}$ & - & & & & \\
4. Goodness & -.105 & $.566^{* *}$ & $.945^{* *}$ & - & & & \\
5. Intelligence & .023 & $.296^{* *}$ & $.219^{* *}$ & $.268^{* *}$ & - & & \\
6. Outcome & $-.544^{* *}$ & $.454^{* *}$ & $.800^{* *}$ & $.842^{* *}$ & $.185^{*}$ & - & \\
7. Romantic involvement & -.105 & $.696^{* *}$ & $.380^{* *}$ & $.368^{* *}$ & $.252^{* *}$ & $.383^{* *}$ & - \\
8. Socioeconomic status & -.085 & $.353^{* *}$ & .055 & .082 & $.299^{*}$ & .086 & $.260^{* *}$ \\
\hline
\end{tabular}

*Significant at .05 (two-tailed). ${ }^{* *}$ Significant at .01 (two-tailed).

Again, based on Smith et al.'s (1999) findings, two separate 2 (Sex of Character) $\times 3$ (Character Role: central, secondary, or peripheral) one-way ANOVAs were performed, with character attractiveness and character goodness as dependent variables. A significant main effect of character role emerged for portrayals of attractiveness, $F(2,159)=11.01, p=.0001$, $\eta_{\mathrm{P}}{ }^{2}=.12$. Bonferroni's post hoc analyses reveal that central characters in the sample were rated as more attractive $(M=6.45, S D=2.30)$ than were secondary characters $(M=4.56$, $S D=2.25, p=.0001)$ and peripheral characters $(M=4.45, S D=2.25, p=.0001)$. The latter two groups of characters did not differ in PA $(p=1.00)$. Similarly, portrayals of goodness differed 
across character role, $F(2,158)=9.22, p=.0001, \eta_{\mathrm{P}}{ }^{2}=.10$. Specifically, central characters received more favorable ratings on goodness $(M=7.79, S D=2.35)$ than did either secondary characters $(M=5.45, S D=3.08, p=.0001)$ or peripheral characters $(M=5.82, S D=2.65$, $p=.002)$. The latter two groups did not differ on goodness ratings $(p=1.00)$.

A significant main effect also emerged for character gender on ratings of attractiveness, $F(1$, 161) $=8.15, p \leq .005, \eta_{\mathrm{p}}{ }^{2}=.047$. Male characters in the sample were rated as more attractive $(M=5.66, S D=2.75)$ than were female characters $(M=4.57, S D=2.08)$. However, a significant main effect for gender did not emerge for ratings of character goodness, $F(1$, 162) $=0.08, p=.08$.

Based on gender inconsistencies in the initial analyses, the decision was made to eliminate sex of character from the subsequent analyses. However, given that character role was highly related to both attractiveness and goodness of movie character, it was important to assess the degree to which the attractiveness of a character predicted character goodness, independent of role. That is, to test the main hypotheses of the study more directly regarding the beauty bias, five separate hierarchical regression analyses were conducted in which role $(1=$ central, 2 = secondary, 3 = peripheral) and rating of character PA were the predictor variables, while goodness, outcome, aggressiveness, intelligence, and romantic involvement were the criterion variables. Specifically, in Step 1, character role was entered. In Step 2, PA ratings were entered to determine how much more of the variance could be accounted for by attractiveness of characters. In Step 3, cross-product interaction terms (PA × Role) were entered.

For character goodness, role of character accounted for $5 \%$ of the variance, $F(1,159)=9.05$, $p=.003$. On Step 2, the main effect of PA was entered into the equation and accounted for an additional $27 \%$ of the variance in goodness, $F(1,158)=63.53, p=.0001$. The interaction of role and beauty failed to account for any additional variance in goodness, $F(1,157)=1.78, p=.184$ (see Table 4). 
Table 4

\begin{tabular}{|c|c|c|c|c|c|}
\hline Variable & $B$ & $S E$ of $B$ & $\beta$ & $t$ & $p$ \\
\hline \multicolumn{6}{|l|}{ Step 1} \\
\hline Role & -.86 & .29 & -.23 & -3.01 & $.003^{* *}$ \\
\hline \multicolumn{6}{|l|}{ Step 2} \\
\hline Role & -.26 & .25 & -.07 & -1.02 & .311 \\
\hline Beauty & .66 & .08 & .55 & 7.97 & $.000^{* *}$ \\
\hline \multicolumn{6}{|l|}{ Step 3} \\
\hline Role (R) & -.99 & .61 & -.27 & -1.64 & .104 \\
\hline Beauty (B) & .37 & .23 & .31 & 1.62 & .108 \\
\hline $\mathrm{R} \times \mathrm{B}$ & .14 & .10 & .28 & 1.34 & .184 \\
\hline
\end{tabular}

Note. $N=163 . R^{2}=.05$ for Step $1 ; R^{2} \mathrm{D}=.27$ for Step $2, p<.01 ; R^{2} \mathrm{D}=.01$ for Step 3, ns.

We conducted an identical regression analysis to predict outcome of character. Character role accounted for $9 \%$ of the variance of outcome, $F(1,156)=14.52, p=.0001$. On Step 2, the main effect of PA was entered into the equation and accounted for an additional $15 \%$ of the variance in outcome, $F(1,155)=29.49, p=.0001$. The interaction of role and PA failed to account for any additional variance in outcome, $F(1,154)=1.24, p=.27$.

Role of character accounted for an insignificant portion of the variance in ratings of aggression $(2 \%), F(1,159)=2.61, p=.11$. On Step 2, the main effect of PA was entered into the equation and accounted for an additional $9 \%$ of the variance in aggression, $F(1,158)=15.78, p=.0001$. Again, the interaction of role and PA failed to account for any additional variance in aggression, $F(1,157)=0.41, p=.52$.

Similarly, role of character accounted for an insignificant portion of the variance for ratings of intelligence $(1 \%), F(1,157)=2.17, p=.14$. On Step 2, the main effect of PA was entered into the equation and accounted for an additional $8 \%$ of the variance in intelligence, $F(1$, $156)=12.81, p=.0001$. The interaction of role and PA failed to account for any additional variance in intelligence, $F(1,155)=0.22, p=.64$.

We also conducted a regression analysis to predict romantic involvement of a character. Role of character accounted for $11 \%$ of the variance of romantic involvement, $F(1,151)=19.49$, $p=.0001$. On Step 2, the main effect of PA was entered into the equation and accounted for an additional $39 \%$ of the variance in romantic involvement, $F(1,150)=119.61, p=.0001$. The interaction of role and PA accounted for another $4 \%$ of the variance in romantic involvement, $F(1,149)=14.04, p=.0001$. 


\section{DISCUSSION}

Study 1 examined the prevalence of the beauty-goodness stereotype as depicted in the human characters in animated Disney films. As predicted, central characters were portrayed more favorably with regard to goodness and were generally rated as more physically attractive than were secondary or peripheral characters across films. In addition, PA of a character predicted how positively the character was portrayed, above and beyond the character's role. These finding are consistent with previous research on top-grossing, non-animated movies (Smith et al., 1999).

Across the animated movies, attractive characters displayed higher intelligence, lower aggressiveness, and greater moral virtue. Moreover, physically attractive characters were more likely to achieve positive life outcomes at the film's end and were more likely to be romantically involved. Thus, anecdotal accounts of Disney's presentation of the PA stereotype appear to be warranted, and not simply the result of selective attention to a handful of popular characters.

Interestingly, the tendency to pair attractiveness and intellectual competence in these movies is in contrast to existing literature showing that adults have only a moderate expectation that physically attractive individuals tend to be more intelligent than less attractive individuals (Eagly et al., 1991). What is not discernible from our current investigation is whether the film data are a result of filmmakers' intentional or unintentional depiction of attractive characters as brighter than unattractive characters, or a moderate expectation on the part of our raters to view more attractive characters as more intelligent.

Much like Smith et al.'s (1999) research, animated Disney films also demonstrated that attractive characters were more likely to achieve positive life outcomes than were characters that were not as physically attractive. In some of the earliest research on the PA stereotype, Dion et al. (1972) similarly found that individuals who were physically attractive were expected to experience more happiness in their lives (e.g., happier marriages, more professional success) than were less attractive individuals. More contemporary research on beliefs about attractiveness further supports such expectations. Evans (2003), for example, showed that women tend to believe that professional female models (who embody idealized attractiveness and thinness) are happier than are average females. Thus, the animated films of Disney seem to maintain and promote the belief that attractive people attain more overall positivity in their lives. Investigations of whether attractive individuals hold actual advantages over less attractive individuals has shown that although they do tend to be less socially anxious, they do not experience better mental health than individuals who are less attractive (Feingold, 1992).

We did not find the expected interaction between the centrality of a character's role and attractiveness across variables. The one exception to this was for romantic involvement. That is, in Disney movies, romantic involvement is depicted for central characters that are attractive. While intentions may have been to spend more time on the character development of those characters, young audiences may infer that such romantic outcomes only occur for attractive individuals. Indeed, previous research has shown that attractive individuals report being less lonely and more popular than unattractive individuals (Feingold, 1992). However, attractive 
women have also been shown to experience higher levels of narcissism and have higher rates of divorce than do less attractive women (Kaner, 1995).

Although Bazzini, McIntosh, Smith, Cook, and Harris (1997) found that in top-grossing films from 1940 to 1989, there were twice as many male characters as female characters, this was not the case for animated Disney films. Of the 163 characters included in the study, 103 were females. Not only were women well represented in these films, they also were portrayed as equally good and equally aggressive as the male characters. Unfortunately, the small number of films included in this study $(\mathrm{N}=21)$ limits the study's generalizability to all animated and nonanimated children's movies. As there was a limited pool of animated Disney films that opened at the box office and that also had ratable human characters, the sample size was somewhat compromised. Thus, future studies should address the PA stereotype across a larger body of animated children's movies.

Furthermore, there is the possibility of an independence violation within this study. Statistical independence is defined as the probability that one event does not depend on whether or not another event occurred (Rees, 1995). Unlike Smith et al. (1999), who analyzed one character from each of the 100 films included in their sample, the current study's analysis included all rated characters from each film. Including only one character from each film would have contributed to a substantial reduction of our sample size. On the other hand, although characters could have influenced one another's ratings within a given film, real-world judgments of others generally do occur in more complicated sequences of behaviors between individuals of varying physical attractiveness.

In summary, Study 1 demonstrated clear support for the depiction of the beauty-goodness stereotype in a sample of animated Disney movies. Since these movies are primarily marketed toward children, we conducted a second investigation to assess the potential influence of such films on children's judgments of peers, just as Smith et al. (1999) did for adults.

\section{STUDY 2}

Use of the PA stereotype is not a phenomenon limited to adults. Indeed, evidence of a biological basis for the preference for attractiveness has been shown in several investigations with young infants. For example, Langlois et al. (1987) showed babies who were 2 to 3 months old or 6 to 8 months old side-by-side slides of photographs of attractive and unattractive women. The results demonstrated that both younger and older infants looked longer at the photographs of attractive faces than at the photographs of unattractive faces. Furthermore, the 6-to-8-month-old infants continued to show a preference for attractive faces over unattractive faces when the photographs were shown one at a time, challenging the view that attractiveness-based standards and preferences are learned over time through gradual exposure to current stereotypes associated with appearance. Given that it is unlikely that babies younger than 8 months have learned such a preference, the findings demonstrate that the preference for PA individuals is, to some extent, innate (also see Langlois, Roggman, \& Rieser-Danner, 1990; Ramsey \& Langlois, 2002). 
Research with older children has also illustrated the prevalence of the PA stereotype in judgments of peers. For example, Langlois and Stephan (1977) showed multi-ethnic kindergarteners and fourth graders photographs of other children previously rated as attractive or unattractive. They found that across racial groups, the attractive photos were judged more favorably on assessments of sharing, friendliness, smartness, and other social skills, as compared to the unattractive photos.

Despite a biological propensity for the stereotype, there is little doubt that the environment encourages the preference by means of socializing agents (e.g., peers, parents, caregivers, teachers), who expose children to their own values and beliefs. Furthermore, there is growing evidence that young children in contemporary American society are exposed to increasing amounts of media sources. In one of the first comprehensive studies of media access and exposure among infants and children, Vandewater et al. (2007) found that one fifth of 0- to 2year-olds and one third of 3- to 4-year-olds had a television, videocassette recorder, or both in their bedrooms. Furthermore, the extent of media saturation is clearly illustrated by the finding that $68 \%$ of infants view television daily, despite the American Academy of Pediatrics' (AAP, 2001) guidelines for no television exposure prior to age 2. Children's level of familiarity with media access was also indicated by the report that more than half of the 0- to 2-year-olds and over $80 \%$ of children between the ages of 3 and 6 could turn on the television by themselves, with many also capable of putting in a video or DVD by themselves. Interestingly, these findings did not vary according to ethnicity, family income, or parental education (Vandewater et al., 2007).

Robinson et al. (2007) argued that Disney films are a prime outlet for children's media consumption as a result of their availability on DVDs and videos, which allows for their frequent in-home viewing. Giroux (1995) speculated that Disney is more than just entertainment. He suggested that popular culture (portrayed through such films) is a powerful educational force, teaching children cultural norms, regardless of parental background. Even the subtle messages in children's media become ingrained when children watch films dozens of times, as children often do (Robertson, 1998). The content of Disney movies has received increasing attention by researchers (e.g., Towbin, Haddock, Zimmerman, Lund, \& Tanner, 2003). However, despite speculation regarding the influence that Disney films have on children, empirically based research assessing their influence on stereotype-related judgments of others has not been conducted to date.

Research with adults has shown that a single exposure to a film that strongly endorses the PA stereotype can temporarily increase the use of the stereotype when judging another adult. Specifically, Smith et al. (1999) had participants view a movie either highly biased in its portrayal of the beauty-goodness stereotype or a movie that did not portray the stereotype. Participants then evaluated two fictitious graduate school applicants who were comparable in their qualifications, but who varied on physical attractiveness. Smith et al. found that although participants generally favored the attractive applicant over the unattractive applicant, the extent of discrimination between the two was exacerbated by the viewing of the highly biased film. 
The purpose of the current study is to assess whether children will be similarly influenced by a single exposure to an animated Disney film that is either stereotypical in its portrayal of characters or nonstereotypical in its portrayal of the PA stereotype. There is reason to argue that the viewing of a single stereotype-consistent versus nonstereotype-consistent film would be less potent for a child than for an adult on subsequent peer judgment.

Heyman and Gelman (2000) proposed that when young children receive appearance information about a protagonist, even if they receive trait information that is potentially contradicting of the PA stereotype, they may reinterpret the PA-contradicting information and reconcile the inconsistency. They used the example of an ugly, "witchlike" woman who engages in an ostensibly kind act and suggested that children may ultimately infer that the woman is performing this action for some ulterior motive (e.g., as part of a trick). Although this tendency decreases with age, as older children begin to rely more on behavioral information in making judgments (Hoffner \& Cantor, 1985), it demonstrates that the viewing of a film with neutral or even contrasting messages about appearance and behavior-for example, Smith et al.'s (1999) low-bias film condition-may be more difficult for a child to process, as compared to an adult.

Similarly, the developmental progression of a stereotype (e.g., PA bias) would predict that children's more simplistic representations of concepts might be less susceptible to priming, relative to adults. Ramsey and Langlois (2002) proposed that children are likely to encode, process, and recall information when it conforms to already existing knowledge and schemas about the world. Information that is inconsistent with pre-existing schemas (in this case, the belief that what is beautiful is good) may be disregarded or inaccurately processed. For example, in two studies, Ramsey and Langlois presented children with stories that varied the physical attractiveness of a character, as well as his or her character positivity. Thus, some of the stories portrayed information that was consistent with the beauty-goodness stereotype, whereas other stories presented information that was inconsistent with the stereotype. The results of both studies showed that when later asked to recall which characters displayed positive traits, children made more errors when the stories were inconsistent with the beautygoodness stereotype.

The present study randomly assigned children between the ages of 6 and 12 to watch a highPA or low-PA biased film and then had them evaluate two peers of varying physical attractiveness on a variety of behavioral measures. We selected this age group primarily because of the ecological validity of the sample. That is, making peer evaluations likely would have occurred for them at some point in their experiences. We divided the children into two categories: a younger group (ages 6 to 9) and an older group (ages 10 to 12) because previous research has shown that the preference for attractive faces becomes more pronounced as children develop (Kissler \& Bauml, 2000).

The resulting design was a 2 (Movie Type: low bias vs. high bias) $\times 2$ (Age of Child: younger vs. older) $\times 2$ (Target Attractiveness: low vs. high) mixed factorial. Unlike the findings of Smith et al.'s (1999) adult sample, we predicted a main effect for attractiveness of target that would not be qualified by movie type or age. That is, a single exposure to a high- or low-bias film would 
not influence peer judgments. However, age was deemed an important variable to include for exploratory purposes.

\section{METHOD}

\section{Participants}

We recruited 42 children ( 21 males, 21 females) between the ages of 6 and 12 from a midsized, southeastern college-campus community via advertisements in a local television station and local newspapers. Children were invited to participate in a 2-hr study on the effects of videos on making friends, with a $\$ 20$ incentive for participation. Parents were required to accompany their children to the study. Of the parents, $5 \%$ reported a household income of $\$ 10,000-30,000,42 \%$ reported an income of $\$ 30,000-60,000$, 33\% reported an income of $\$ 60,000-90,000$, and $14 \%$ reported an income over $\$ 90,000$ (7\% of the sample did not report a household income range). Authorization to conduct this investigation was granted by the university's Institutional Review Board. All procedures adhered to the ethical guidelines of the APA (2002).

\section{Materials}

Movie selection. Modeled after Smith et al.'s (1999) investigation of whether exposure to stereotypical representations of the PA stereotype would influence adults' perceptions of an attractive versus unattractive target, we selected two films from Study 1 that either depicted a high degree of beauty stereotyping or a low degree of stereotyping. The children who were randomly assigned to the high-bias film condition watched Cinderella (intra-movie beautygoodness correlation was $r=.92$ ). There were two other movies (Lilo and Stitch and The Rescuers) that had beauty-goodness correlations similar to Cinderella. However, Lilo and Stitch had a PG (Parental Guidance Suggested) rating, which we deemed inappropriate to show to our younger viewers, and The Rescuers (rated G for General Audience) had only three rated human characters whereas Cinderella (rated $G$ ) had eight rated human characters.

The children who were randomly assigned to the low-bias film condition watched The Hunchback of Notre Dame (intra-movie beauty-goodness correlation was $r=.07$ ). This was the only movie to yield both the requisite correlation coefficient (almost zero) for the low-bias condition as well as a $\mathrm{G}$ rating. The only other movie with such a low beauty bias correlation was Atlantis ( $r=.02)$ and that movie was rated PG. The Hunchback of Notre Dame had six rated human characters; thus, our high-bias and low-bias movies had a similar number of rated characters and were both rated $G$. Ratings of children's liking for the high- and low-bias movies after viewing showed no difference between the two films, $t(39)=-0.82, p=.41$.

Photographs. We selected 12 yearbook-like photographs of children (6 males, 6 females) from an initial pool of 56 photographs. The photographs were rated on a 10-point scale ranging from 1 (unattractive) to 10 (attractive) by a class of 23 undergraduate students. Of the 12 selected photographs, 4 depicted children in the 6-to-8-year-old age range, 4 depicted children 
in the 9-to-10-year-old age range, and 4 depicted children in the 11-to-12 year-old age range. For each age range represented and for both genders, a photograph rated as high on physical attractiveness and a photograph rated as low on physical attractiveness were selected. Across ages and gender, photographs used for the attractive target condition ranged from 6.90 to 8.04 (on a 10-point attractiveness scale), whereas those used for the unattractive condition ranged from 3.39 to 4.49 .

Target assessment and demographic questionnaire. We created a short questionnaire to assess children's interpersonal perceptions of the target photographs. Given the variability in children's ages, we chose to include measures with a more behavioral, rather than a temperamental assessment of the targets (similar to items used by Langlois \& Stephan, 1977). Items were rated on a 4-point scale ranging from 1 (least) to 4 (most) and included "How nice would you say this person is?"; "How often would you say this person gets into trouble at school?"; "How much do you think other kids would want to be friends with this person?"; and "How much would you like to be friends with this person?" Cronbach's alphas for the four-item scale were .70 and .79 for the attractive photographs and the unattractive photographs, respectively (range $=4-16$ ). Thus, we created a composite assessment score for each photograph.

An additional item asked participants to choose the person (from the two photographs) with whom they would most want to be friends. Demographic information was reported by parents.

\section{Procedure}

Children were run in groups of 3 or 4 . Upon their arrival to the study site, the children were escorted to the movie-viewing area. Parents were then privately instructed as to the purpose of the study and were asked to complete the consent forms. They were also asked to provide demographic information about their children and their families.

Each small group of children was then randomly assigned to watch either the high-bias (Cinderella) or the low-bias film (The Hunchback of Notre Dame). Following the viewing of the film, the children were asked to indicate how much they liked the film on a 4-point scale ranging from 1 (not at all) to 4 (extremely). The children were then individually presented with two photographs. One of the photographs was of a same-age, same-gender peer, previously rated as high on attractiveness; the other was of a same-age, same-gender peer, previously rated as low on attractiveness. The order of presentation of photographs was counterbalanced. The participants were then asked to make the behavioral ratings of each photograph, as well as the forced-choice friendship preference measure. Because children's ages varied, an experimenter read each question to the child and wrote down the responses for the child.

Following completion of the tasks, parents and children were brought back together and were fully debriefed. Questions were answered about the study, and participants were paid \$20 prior to leaving the study. 


\section{RESULTS}

To assess whether exposure to the PA stereotype would intensify children's use of the PA stereotype in judgments of a peer, we conducted a 2 (Movie Type: high bias vs. low bias) $\times 2$ (Age of Child: younger vs. older) $\times 2$ (Target Attractiveness: high vs. low) mixed-subjects ANOVA, using the composite peer assessment score (range $=4-16$ ) as the dependent variable. The analysis reveals a main effect for target attractiveness such that children across age groups rated the attractive target $(M=12.17, S D=1.96)$ more favorably than the less attractive target $(M=11.45, S D=2.32), F(1,38)=51.39, p=.0001, \eta_{\mathrm{P}}{ }^{2}=.58$.[3] No significant effect occurred for type of movie watched, nor did any significant interactions emerge between variables (all $F s<4, n s$ ).

Finally, a forced-choice friendship selection was used as a behavioral measure of the PA stereotype. The choice of which peer target the child would prefer as a friend was submitted to a 2 (Target Attractiveness: high vs. low) $\times 2$ (Movie Type: high bias vs. low bias) chi-square analysis. The analysis yielded one significant effect. Regardless of which movie was viewed, children who expressed a preference preferred the attractive target as a friend (78\%) over the unattractive child $(22 \%), x^{2}(1,27)=8.33, p=.004$. It should be noted that $36 \%$ of the sample of children did not show a preference for either target. In no case did movie type significantly alter friendship choice.

\section{DISCUSSION}

The findings of Study 2 replicate previous research demonstrating that children, like adults, show a preference for attractive over unattractive peers and rate them more positively (Cavior \& Lombardi, 1973; Kissler \& Bauml, 2000; Langlois \& Stephan, 1977). Indeed, children in the current study reported an overall greater desire to befriend an attractive peer and rated the child as more likely to be desired as a friend by other children, less likely to get into trouble, and nicer, relative to an unattractive peer. As predicted, this propensity toward the beauty-goodness stereotype was not intensified by recent media exposure. That is, a single viewing of an animated Disney film depicting a strong correlation between the goodness and beauty of its characters did not lead children to make more favorable evaluations of an attractive peer (or less favorable evaluations of an unattractive peer), relative to children who had viewed a film that was nonstereotypical in its depictions of the beauty-goodness stereotype.

These results are noteworthy, given that they are inconsistent with research using adults. Smith et al. (1999) found that when adults were exposed to a movie that portrayed a high correlation between the attractiveness and goodness of its characters, the adults were more positive in their evaluation of a graduate school applicant who was attractive than were those who had a viewed a film that did not demonstrate a high beauty-goodness correlation. Thus, it appears that priming of the stereotype worked for adults, but not for children. 
One reason for adults' seemingly greater vulnerability to exposure to the PA stereotypeconsistent versus the stereotype-inconsistent film is the progression of stereotype formation from a developmental perspective. Recall that Ramsey and Langlois (2002) demonstrated that counterstereotypical information about a target related to the beautiful-is-good stereotype may be incorrectly interpreted or even disregarded by children. They found that this was particularly the case when recalling information about female characters. Children showed a propensity to report that attractive female characters displayed positive traits, even when this was not the case in the story. They suggested that such distortions in the processing of stereotypeinconsistent information likely maintain the beauty-goodness stereotype and the greater emphasis that is placed on physical attractiveness for women. For the children in our study, it is possible that those who watched the low beauty bias film may have disregarded or failed to process information that would have disconfirmed the belief that the attractive individuals in a given film, particularly women, were not, in fact, the most desirable characters morally.

The fact that Ramsey and Langlois' (2002) results were more indicative of recalled information for female characters than for male characters is also relevant to our investigation, given the disproportionate number of female to male characters that our first investigation revealed for animated Disney films. Of the characters across our selected movies, $63 \%$ were female. Thus, children will be very likely to attend to stereotypical depictions of females in these films, and potentially misrepresent the nonstereotypical depictions, failing to alter the developing stereotype associating beauty and goodness for women. This suggests that even nonstereotypical portrayals of female characters will have little impact on child viewers.

Another potential explanation for the discrepancy between our findings with children and those of Smith et al.'s (1999) adult participants might be our participants' greater familiarity with the movies themselves. Smith et al.'s college-aged viewers watched either Pride of the Yankees or Road to Utopia under conditions of high bias, and Up the Down Staircase or Rhapsody in Blue under conditions of low bias. These films' release dates ranged from 1942 to 1967, so given the age range of the sample, it is not likely that these were films that had been watched frequently prior to the experimental exposure by early-20-year-olds in the late 1990s. By contrast, more than $85 \%$ of the children in our sample reported that they had seen either the low- or high-bias film at least once. Indeed, as stated earlier, Disney films are typically watched repeatedly by children. So, it is possible that the level of previous exposure to these films created a qualitatively different experience for this study's child sample versus Smith et al.'s adult sample. Future research should address how familiarity with a stimulus might influence its impact on the maintenance and use of the beauty-goodness stereotype.

Previous research might have predicted an age difference among our children for the impact of exposure to the high-bias film, relative to the low-bias film. Hoffner and Cantor (1985) exposed children of varying ages (3 to 5 years old, 6 to 7 years old, and 9 to 10 years old) to a video involving an ugly versus an attractive female protagonist engaging in either a cruel or a kind act and then asked them to make judgments about the protagonist. Older children were less influenced by the protagonist's appearance than were the younger children and were more influenced by her behavior. For example, younger children rated an ugly-kind woman as nominally more mean than an attractive-cruel woman, a clear demonstration of difficulty in 
processing counterstereotypical information. This might suggest that younger children would have been more receptive to the messages promoted in the high-bias film, relative to older children in our sample.

However, unlike Hoffner and Cantor's (1985; also see Ramsey \& Langlois, 2002) investigations, which utilized a methodology that involved children evaluating a single target in a story, or perhaps two targets concurrently with contrasting appearance and behavioral valence, the stimuli in this study exposed children to multiple characters concurrently. That is, children watched movies that involved a more complicated array of appearance and behavioral messages that had to be processed simultaneously. Even for our "older" children (ages 10-12), we believe that this more sophisticated processing argued for less influence by a single movie exposure.

\section{GENERAL DISCUSSION}

Taken together, the current investigations empirically support the anecdotal observations that animated Disney movies promote the stereotype that what is beautiful is good. Indeed, in some Disney films, attractive characters are portrayed as being more morally virtuous and less aggressive, and as achieving more positive life outcomes than unattractive characters. However, our second investigation demonstrated that children between the ages of 6 and 12 evaluated a peer who was attractive more favorably than an unattractive peer, regardless of whether they had viewed a film that endorsed or did not endorse the stereotype. It may seem heartening to many parents that a single movie viewing did not induce greater use of the stereotype; however, this may be a result of the fact that the stereotype-inconsistent depictions of the low beauty bias film are simply not potent enough to unravel a steadily developing propensity to judge attractiveness positively, especially when such stereotypes involve females.

Contemporary society's increasing reliance on the use of television and videos to occupy children warrants continued investigation of how exposure to media may affect children. Vandewater et al. (2007) found that a commonly cited reason for why parents allow children, even those younger than 2 years old, to watch television is to enable parents to get other things accomplished around the home. Given that media portrayals like those in the animated movies of Walt Disney often reinforce societal stereotypes related to gender, ethnicity, and culture (Towbin et al., 2003), parents may consider a more thoughtful approach to the use of television and videos. Towbin et al. suggested that some parents may benefit from being "coached" by mental health professionals to help children recognize and understand the racial, social, and gender-based stereotypes that may be promoted by media sources. It is unclear whether parents commonly use movies and television to prompt a dialogue with their children about stereotypes or other information relevant to their children's daily interactions.

It is clear that the growing pervasiveness of media in the world of children has the potential for negative and positive outcomes. Parents, teachers, and mental health professionals are now navigating resources that previously were not available or so widely accessible to children. 
Researchers should continue to assess how advancements in the use of technology concurrently and prospectively influence the development of children.

\section{REFERENCES}

Abramowitz, I., \& O'Grady, K. (1990). Impact of gender, physical attractiveness, and intelligence on the perception of peer counselors. The Journal of Psychology, 125, 311-326.

American Academy of Pediatrics. (2001). Children, adolescents, and television. Retrieved June 30, 2008, from http://aappolicy.aappublications.org/cgi/reprint/pediatrics;107/2/423.pdf

American Psychological Association. (2002). Ethical principles of psychologists and code of conduct. Retrieved October 27, 2008, from http://0www.apa.org.wncln.wncln.org/ethics/code2002.html

Bazzini, D. G., McIntosh, W., Smith, S., Cook, S., \& Harris, C. (1997). The aging woman in popular film: Underrepresented, unattractive, unfriendly, and unintelligent. Sex Roles: A Journal of Research, 36, 531-544.

Cash, T., \& Kilcullen, R. (1985). The eye of the beholder: Susceptibility to sexism and beautyism in the evaluation of managerial applicants. Journal of Applied Social Psychology, 15, 591-605.

Cavior, N., \& Lombardi, D. A. (1973). Developmental aspects of judgment of physical attractiveness in children. Developmental Psychology, 8, 67-71.

Chen, N., \& Shaffer, D. (1997). On physical attractiveness stereotyping in Taiwan: A revised sociocultural perspective. Journal of Social Psychology, 137, 45-51.

Dion, K., Berscheid, E., \& Walster, E. (1972). What is beautiful is good. Journal of Personality and Social Psychology, 24, 285-290.

Disney Acquires Club Penguin. Retrieved August 29, 2007, from http://corporate.disney.go.com/news/corporate/2007/20070801clubpenguin.html

Downs, A., \& Harrison, S. (1985). Embarrassing age spots or just plain ugly? Physical attractiveness stereotyping as an instrument of sexism on American television commercials. Sex Roles: A Journal of Research, 13, 9-19.

Eagly, A., Ashmore, R., Makhijani, M., \& Longo, L. (1991). What is beautiful is good, but . ..: A meta-analytic review of research on the physical attractiveness stereotype. Psychological Bulletin, 110, 109-128.

Evans, P. C. (2003). "If only I were thin like her, maybe I could be happy like her": The selfimplications of associating a thin female ideal with life success. Psychology of Women Quarterly, 23, 209-214. 
Farley, S., Chia, R., \& Allred, L. (1998). Stereotypes about attractiveness: When beautiful is not better. Journal of Social Behavior and Personality, 13, 479-493.

Feingold, A. (1992). Good-looking people are not what we think. Psychological Bulletin, 111, 304-341.

Giroux, H. (1995). Animating youth: The Disneyfication of children's culture. Socialist Review, 24, 23-55.

Heyman, G. D., \& Gelman, S. A. (2000). Preschool children's use of trait labels to make inductive inferences. Journal of Experimental Child Psychology, 77, 1-19.

Hoffner, C., \& Cantor, J. (1985). Developmental differences in responses to a television character's appearance and behavior. Developmental Psychology, 21, 1065-1074.

Kaner, A. (1995). Physical attractiveness and women's lives: Findings from a longitudinal study. Dissertation Abstracts International: Section B. The Sciences and Engineering, 56(5-B).

Kissler, J., \& Bauml, K. (2000). Effects of the beholder's age on the perception of facial attractiveness. Acta Psychologica, 104, 145-166.

Langlois, J., Roggman, L., Casey, R., Ritter, J., Rieser-Danner, L., \& Jenkins, V. (1987). Infant preferences for attractive faces: Rudiments of a stereotype? Developmental Psychology, 23, 363-369.

Langlois, J., Roggman, L., \& Rieser-Danner, L. (1990). Infants' differential social responses to attractive and unattractive faces. Developmental Psychology, 2, 153-159.

Langlois, J. H., \& Stephan, C. (1977). The effects of physical attractiveness and ethnicity on children's behavioral attributions and peer preferences. Child Development, 48, 1694-1698.

Myers, D. G. (2002). Social psychology (7th ed.). Boston: McGraw-Hill.

Ramsey, J., \& Langlois, J. (2002). Effects of the "beauty is good" stereotype on children's information processing. Journal of Experimental Child Psychology, 81, 320-340.

Rees, D. G. (1995). Essential statistics (3rd ed.). New York: Chapman \& Hall.

Robertson, G. (1998). Snow Whitey? Canadian Dimension, 32, 42-44.

Robinson, T., Callister, M., Magoffin, D., \& Moore, J. (2007). The portrayal of older characters in Disney animated films. Journal of Aging Studies, 21, 203-213.

Smith, G., \& Thompson, A. (1996). Is bigger better? Film Comment, 32, 60-64.

Smith, S., Mclntosh, W., \& Bazzini, D. (1999). Are the beautiful good in Hollywood? An investigation of the beauty-and-goodness stereotype on film. Basic and Applied Social Psychology, 21, 69-80. 
Stemler, S. E. (2004). A comparison of consensus, consistency, and measurement approaches to estimating interrater reliability. Practical Assessment, Research, and Evaluation, 9(4). Retrieved May 19, 2008, from http://pareonline.net/getvn.asp?v=9\&n=4

Towbin, M. A., Haddock, S. A., Zimmerman, T. S., Lund, L. K., \& Tanner, L. R. (2003). Images of gender, race, age, and sexual orientation in Disney feature-length animated films. Journal of Feminist Family Therapy, 15, 19-44.

Vandewater, E. A., Rideout, V. J., Wartella, E. A., Huang, X., Lee, J. H., \& Shim, M. (2007). Digital childhood: Electronic media and technology use among infants, toddlers, and preschoolers. Pediatrics. Retrieved July 30, 2007, from http://pediatrics.aappublications.org/cgi/content/full/119/5/e1006

\section{FOOTNOTE}

3. A main effect for age reveals that younger children $(M=10.82, S D=1.22)$ rated both targets more favorably than did older children $(M=9.70, S D=1.75), F(1,38)=5.79, p=.02, \quad \eta_{\mathrm{p}}{ }^{2}=.13$. Although the greater variability in judgments of older children relative to younger children is consistent with Kissler and Bauml's (2000) finding that distinctiveness in facial preferences increases with age, the finding seems more peripheral to the hypotheses than do the other significant effects. Thus, we will not elaborate on them further. 